\title{
PSYCHE.
}

\section{FRAGMENTS OF THE COARSER ANATOMY OF DIURNAL LEPIDOPTERA.}

\author{
BY SAMUEL H. SCUDDER, CAMBRIDGE, MASS.
}

(Continued from p. 298.)

\section{THE LARVA OF CALLOPHRYS RUBI, OF EUROPE.}

Muscular system. 'The ventral muscular band on each side of the median line is treble, each division of about the same width as the others.

Digestive system. 'The oesophagus enters the stomach with no marked crop, the canal only enlarging slightly to 0.2 $\mathrm{mm}$. diameter just in advance of the stomach, at the end of the second thoracic segment; the stomach is shorter than usual, occupying only one-half the length of the entire canal and ending abruptly at the end of the fourth abdominal segment. It is furnished with longitudinal and transverse muscular fibres, the bands along the middle of the dorsum several in number and more distinct than the others. 'The colon is much slenderer than usual, and about as long as the intestine.

The salivary glands are large, broadly tortuous tubes, their extremities attached near the middle of the thorax to the dorsal vessel.

The malpighian vessels originate in a long and slender, slightly tapering, subcylindrical sac, $0.65 \mathrm{~mm}$. long, lying along the side of the intestine, but attached only by the broader end ; the basal tube arises from the opposite extremity, and branches at a distance from the base of the tube of less than half the length of the sac; the lateral branches are not very closely approximated to the stomach, somewhat irregularly directed, and run as far as the front of the abdomen; the inferior branches extend about the same distance.

Circulatory system. The dorsal vessel is a comparatively large and equal tube, running distinctly as far as the end of the third abdominal segment; at the point where the salivary glands are attached to it, it becomes suddenly, though only slightly, enlarged, and gradually tapers beyond to nearly its former size.

Nervous system. The cephalic lobes are entirely distinct from each other, but in juxtaposition ; each is nearly globular, but a little ovate, about $0.28 \mathrm{~mm}$. long, and as high as broad. The suboesophageal and thoracic ganglia are as broad as long and of nearly the breadth of one of the cephalic lobes, but in the abdomen the ganglia grow slenderer in passing backward, so that at last they are hardly broader than the cord, and scarcely to be distinguished from it by anything more than their greater opacity and depth. The fourth and fifth body-ganglia are scarcely nearer together than the first and second, the fourth lying midway between the third and the sixth ; 
the third and fourth are slightly more than one millimetre apart, and separated by a slightly greater distance than any two of the abdominal ganglia; the angle of the cords between the third and fourth body-segments is much nearer the latter than in Danais; the last two ganglia are so closely united as to appear as one long ganglion, and they are not quite so far removed from the tenth ganglion as that is from the ninth. In at least the abdominal segments, the lateral nerves are thrown off from the cord at a distance from the ganglia equal to the width of the cord.

Glandular system. The silk vessels pass as slender, broadly curving, but not tortuous, thread-like tubes beside the intestinal canal for some distance, when they curve inward so as to meet beneath the stomach and run side by side, expanding rapidly and greatly to a cylindrical tube $0.3 \mathrm{~mm}$. in diameter in the front half, about half that in the posterior portion as far as the middle of the second abdominal segment; here each diminishes rapidly in size, suddenly turns back upon itself and then, again resuming its former direction, ends in a delicate thread.
Female generative organs. The ovaries, situated in the hinder half of the fifth abdominal segment, are $0.4 \mathrm{~mm}$. long, oblong ovate in shape, and of a white color.

Rudiments of wings. The wing-pads of the mature larva are nearly circular, flattened disks, a little more than a millimetre in diameter, directed backward, those of opposite sides turned a little toward each other, the metathoracic overlapping the nearer edge of the mesothoracic, and originating upon the dorsum, so near the median line that the inner edges of those on one side meet the corresponding parts of those on the other, resembling in their disposition the appearance of the wings in the pupae of ephemeridae, and having the very opposite position to that which they will finally assume in their own pupal stage. What is still more to be remarked is that they originate very far from the tracheal trunks, and I did not see that tracheal tubes of any sort passed to them. Traces only of vessels can be seen in their interior, but no such definite arrangement of branching tubes as was noticed in Hamadryas; these did not seem to run to the base of the wing-pad.

\section{LARVA OF EURYMUS PHILODICE, OF. N. AMERICA.}

Muscular system. A set of nearly parallel, but slightly converging bands runs from beneath the insertion of the longitudinal ventral muscular ribbons to the ventral line, terminating at the iniddle of the anterior half of the succeeding segment. As to the dorsal muscles, the three longitudinal strips found on each side of the dorsal line are not con- tinuous from segment to segment; the inner band of each segment broadens posteriorly to cover the base of the inner two of the succeeding segment; the middle band is continuous with the outer of the succeeding segment, and the outer stops altogether at the end of the segment; so that each line of muscles is oblique and extends over three seg- 
ments, being inner on one, middle on the next, and outer on the third; but a portion of the inner remains inner throughout.

Digestive system. 'The salivary glands are $4 \mathrm{~mm}$. long, flat and simple, bent abruptly outward beyond the middle, tapering slightly and regularly to a bluntly rounded tip.

The malpighian vessels originate in an oval gland or sac, $0.4 \check{\mathrm{mm}}$. long and $0.2 \mathrm{~mm}$. broad, a short distance beyond which the under branch is thrown off and immediately afterward the two others. The under branch passes forward in a straight and not a tortuous course, and is proportionally about as long as in Danais; the upper branch extends forward for a distance of $3.75 \mathrm{~mm}$.; the lateral to the point where the silk vessels bend, $7 \mathrm{~mm}$. from its origin.

Nervous system. 'The cephalic lobes are globular. The cords connecting the second and third body-ganglia run together for nearly one-quarter the distance from the second backward, then diverge considerably, and again converging, enter the third ganglion at a perceptible distance apart; nearly the same is repeated between the first and second ganglia, but they diverge nearly from their origin; between the first body-ganglion and the suboesophageal ganglion the cords are parallel, but separate, and a little parted in the middle. The third ganglion lies in the middle of its segment, the fourth at the anterior edge of its segment, and only $0.75 \mathrm{~mm}$. from the third; the fifth in the middle of the anterior half of its segment ; the eleventh ganglion is considerably longer than broad, and the pair of posterior, backwardly directed, diverging nerves is larger than any of the others, and may be looked upon as the continuation of the connecting cords between the other ganglia.

Glandular system. The basal thread of the silk vessels is straight and not tortuous; the basal half of the stouter vessel is flattened; it extends backward as far as the third abdominal segment and then turns abruptly, with a slight forward curve, to the upper side of the body, where it continues in a straight line as far, apparently, as the end of the sixth abdominal segment. The length of the initial thread or duct is $3.25 \mathrm{~mm}$. ; of the portion of the ribbon or vessel upon the under surface $4 \mathrm{~mm}$. ; of that upon the upper surface $5.25 \mathrm{~mm}$.

( To be continued on p. 319.)

\section{COLOR OF 'THE LIGHT EMITTED BY INSECTS.}

BY HENRY WARD TURNER, ITHACA, N. Y.

Some specimens of Pyrophorus noctilucus Linn., from the West Indies, that were brought to the Academy of natural sciences, at Philadelphia, gave out a very bright-green light from the two dorsal prothoracic spots, and also from the ventral surface near the base of the abdomen. Gosse (Ann. and mag. nat. hist., 1848, s. 2, v. 1, p. 200) says they give out a rich yellow-green light when flying and a green light when in captivity. Photuris pensylvanica gives out (sometimes at least) a very decided green light, and Photinus pyralis a yellow light from the ventral surface of the two or three last segments of the abdomen. 

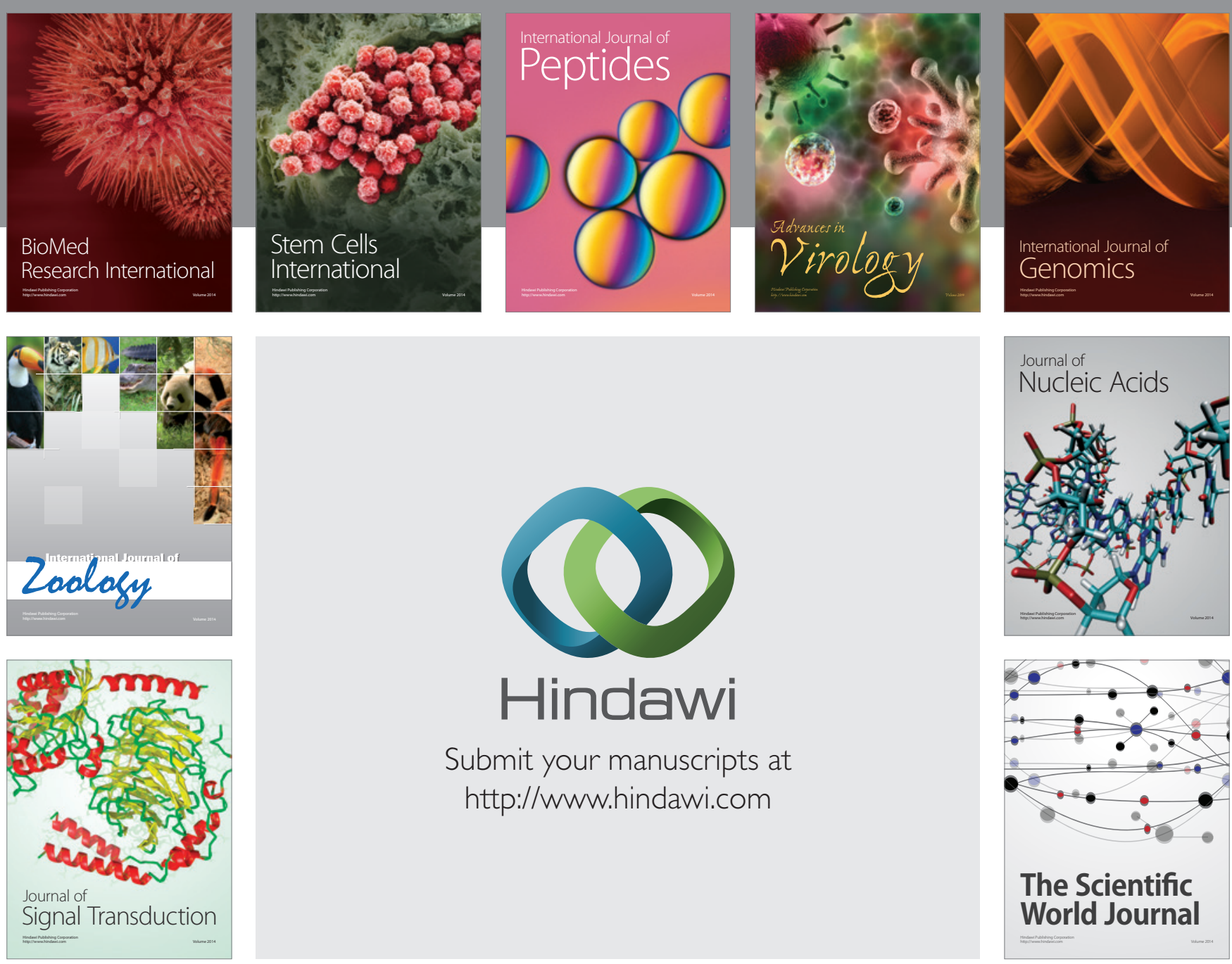

Submit your manuscripts at

http://www.hindawi.com
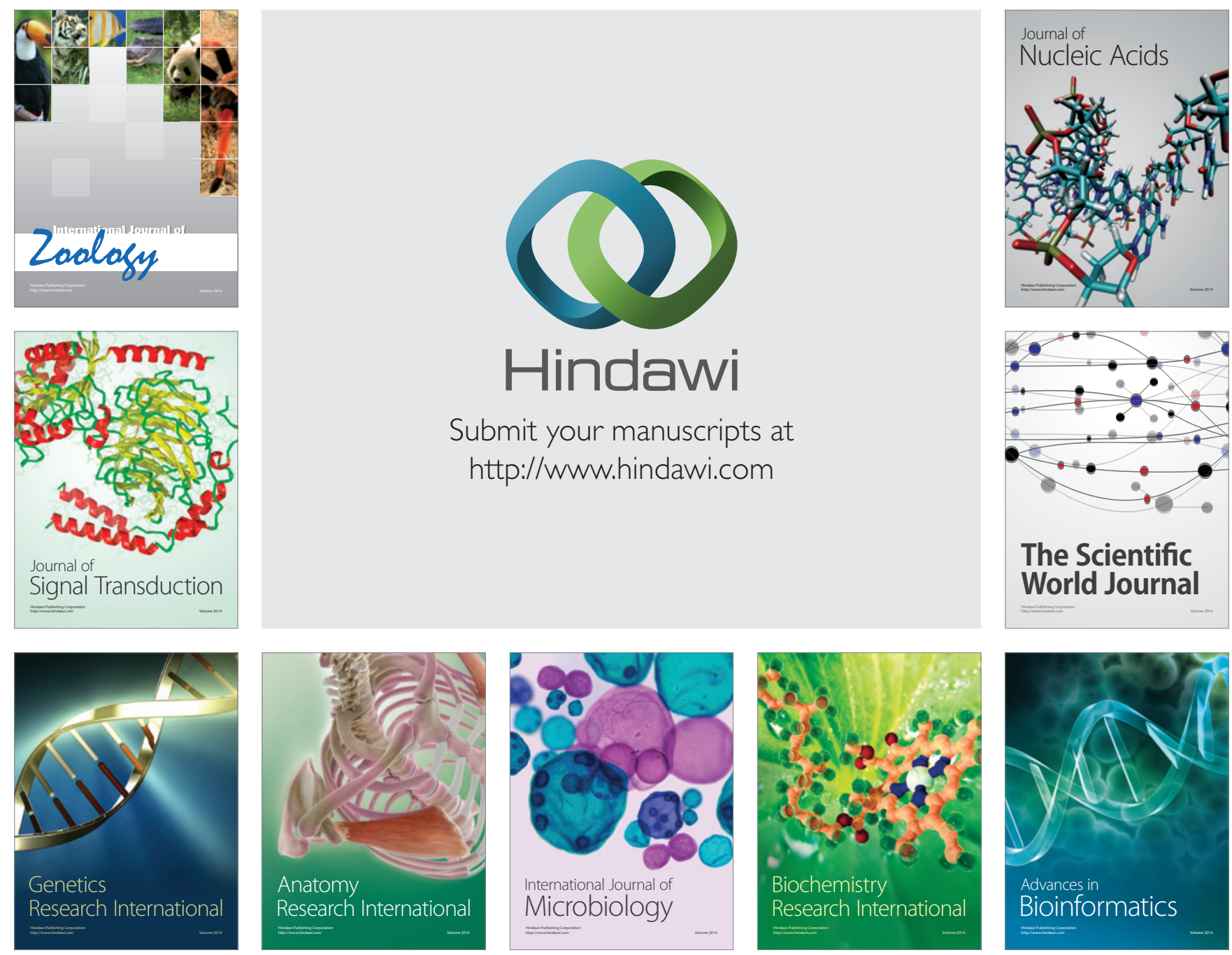

The Scientific World Journal
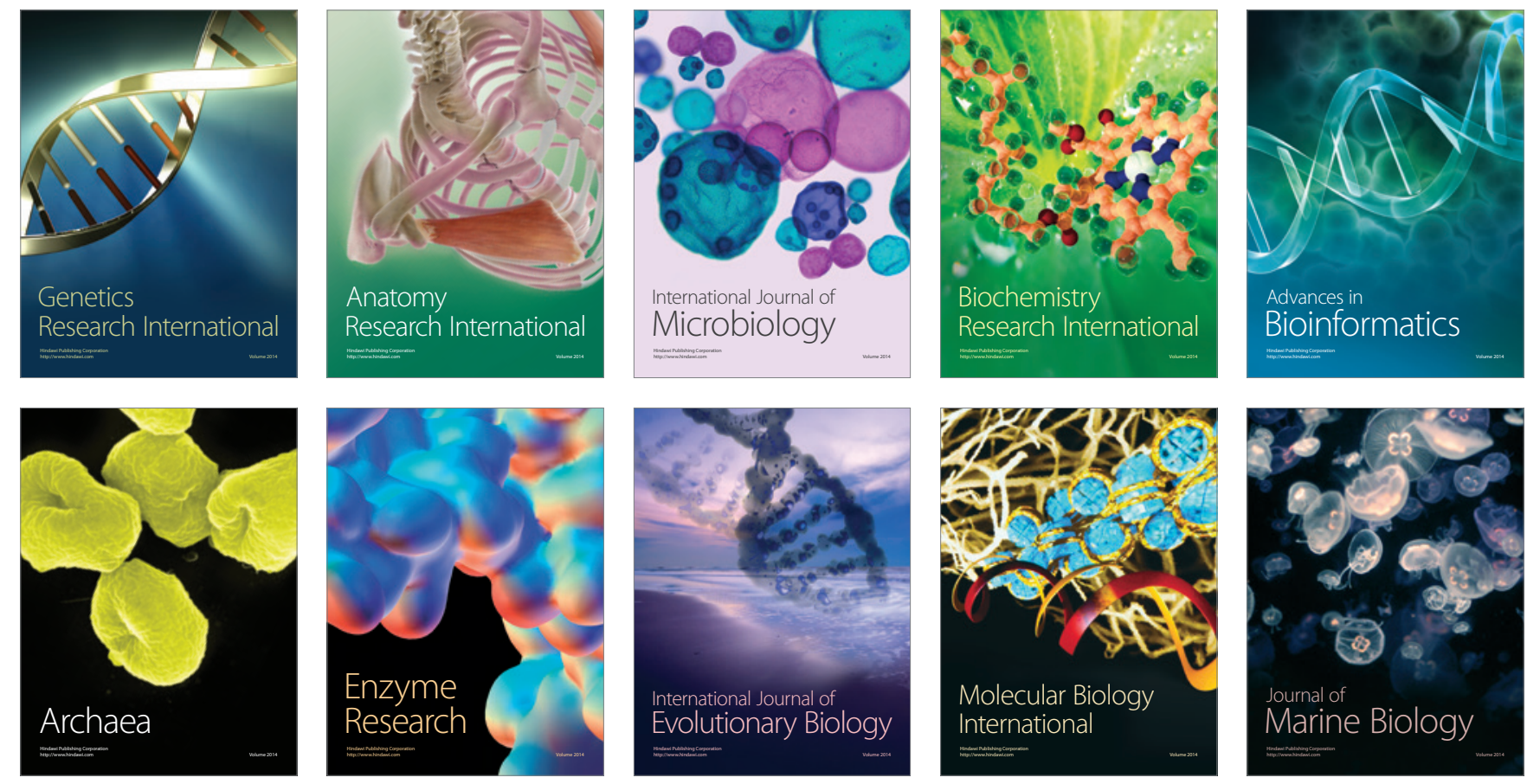